\title{
Mikkel Thorup
}

\section{Rødder og vinger - den nye kosmpolitisme og dens kritikere}

Det er ikke ualmindeligt at opdele politiske filosofier i dem, der har 'rødder' og dem, der har 'vinger'. Dem med rødder fremhæver det konkrete, stedet, det partikulære, det nationale, det altid allerede situerede. De kritiserer dem med vinger for at benægte virkelighedens rodfæstethed. Dem med vinger kritiserer til gengæld dem med rødder for at være indelukkede, fordomsfulde og krampagtigt stationære. De fremhæver i stedet friheden og det universelle; bevægelighed og foranderlighed er grundvilkåret.

Kosmopolitten er altid blevet beskyldt for at have vinger og ingen rødder. Det er de intellektuelles flugt fra det konkrete og forpligtende fællesskabs byrder og begrænsninger. Det er de velhavendes unddragelse af deres (skatte)forpligtelser. Det er elitens retorisk elegante foragt for folket. Det er de fås mulighed på bekostning af de mange. Det er livet for et mindretal og en (ond) drøm for flertallet.

Globaliseringsdebatten har fremmet en renæssance for både kosmopolitismen og dens kritikere. Fra mange sider kritiseres den globale elite som de nye kosmopolitter, der forråder nation og demokrati. Fra ganske andre sider fremhæves kosmopolitismen som svaret på fællesskabets og demokratiets overlevelse i en global tidsalder; som en demokratisering og begrænsning af de globale eliter.

Det er en af denne artikels bærende teser, at der er en stærk modsætning mellem det negative billede af kosmopolitten, som dens kritikere fremmaner, og så den kosmopolitisme, der forsvares i dag af en række fremtrædende intellektuelle. Denne artikel tager dikotomien mellem rødder og vinger op i en diskussion af den nye kosmopolitisme. Det 'nye' angår en selvkritisk besindelse på rødderne i kosmopolitismen. En besindelse, der i det store hele er forblevet uerkendt hos 'rødderne', som fortsat kritiserer den gamle kosmopolitisme med 
billeder fra en svunden (hvis overhovedet eksisterende) kosmopolitisme. Det er det gamle billede, der får en kosmopolitisk (!) sociolog, som Manuel Castells til at kalde den nye globaliserede elite for "identitetsløse individer ('verdensborgere')" (1997: 356). Påstanden er, at de udskifter deres nationale tilhørsforhold med det, Craig Calhoun med et herligt udtryk kalder 'the class consciousness of frequent travelers' (2002). Den nye kosmopolitisme deler den bekymring for den globaliserede uansvarlighed, som Christopher Lasch gav betegnelsen 'eliternes oprør og forræderiet mod demokratiet' (1995), og de forsøger modsat Castells' udsagn både at have en stærk identitet og at være ansvarlige samtidig med, at de er verdensborgere.

\section{Den nye kosmopolitisme: vinger med rodder}

Kosmopolitismens kerne er en mistro overfor det partikulære - bystaten, nationen, racen, klassen etc. Fra sine første manifestationer og til i dag har dens drivkraft været en kritik af indelukkethed, af begrænsede horisonter, af grænser for viden og bevægelighed, af udpegning af fjenden og af hjemmets selvfølgelighed. Påberåbelsen af det universelle og én menneskehed er en kritisk kommentar til det partikulære og den opdelte menneskehed, der, som Hobbes skrev om dens moderne form, står overfor hinanden som jaloux gladiatorer (1985: 187).

Kosmopolitismen angriber grænsers selvfølgelighed og afgrænsede enheders påståede naturlighed; kosmopolitismen mistror fasthed og lukkethed og frygter renhed. Kosmopolitten er altid nysgerrig efter at vide, hvad der ligger på den anden side af grænsen; at møde dem og det, der endnu er ukendt. Han eller hun er en opdagelsesrejsende i sin egen og andres verden, og vedkommende slæber alle indtrykkene med sig og forsøger at gøre verdens mangfoldighed til sin egen horisont og forståelse. Den dybe kilde til kosmopolittens længsel og ubehag er hans eller hendes afvisning af at lade sig begrænse af tilfældet. Det 'tilfældige' sted, hvor man fødes eller bor, må ikke diktere ens hele væren. Man er altid allerede langt mere. 


\section{Kaosmopolis eller verden som by}

Begrebet kosmopolis betyder 'verdensby' eller 'verden som en by', og det udtrykker ganske godt både dens tilhængeres og dens modstanderes billede af kosmopolis. Verden som by vækker både håb om en spændende verden og afsky som syndens og forfladigelsens hjemsted. Kosmopolitten ønsker verden som by, da den tilbyder muligheder, foranderlighed, basarens labyrintiske vrimmel og den menneskelige værens pluralisme. Her er enhver fri til at udtrykke sin individualitet; alt er i stadig bevægelse; alt bydes indenfor. Verden som by er modsætningen til grænsen og begrænsningen.

Antikosmopolitten derimod foragter verden som by som hjemstedet for det upersonlige, det ens og grå, her er alt og alle til salg, livet er fordærvet og forfladiget. Det er markedets og bordellets sted (Buruma \& Margalit, 2004: kap. 2). Denne modstand mod verden som by er del af en større modernitetskritik eller modoplysning, der anfægter det modernes nivellering og forfladigelse; dets opgør med alle forskelle og hierarkier. Ifølge Pierre-André Taquieff installerer moderniteten "det inde-imellem og 'hverken det ene eller det andet', det neutrale og det blandede, det at være hjemme overalt og at være hjemme intetsteds, nomaden og kosmopolitten som normative typer" (1997:162). Det er mod denne manglende forskelssætten mellem køn, racer, nationer, stater, klasser etc., at antikosmopolitismen finder sin motivation.

Derfor er der også en stærk indre sammenhæng mellem på den ene side kosmopolitismen og menneskerettighederne og på den anden side antikosmopolitismen og modstanden mod menneskerettighederne. Den katolske reaktionære oplysningsmodstander, Joseph de Maistre (1753-1821), skrev: "Som dens forgængere blev forfatningen fra 1795 lavet for mennesket. Men der findes ikke en sådan størrelse som mennesket i denne verden. I min livstid har jeg set franskmænd, italienere, russere etc.; takket være Montesquieu ved jeg endda, at man kan vare perser. Men, erklærer jeg, mennesket har jeg aldrig mødt; han er mig ukendt." (1974: 97). Edmund Burke erklærede noget tilsvarende (1987: 59), og også i dag går antikosmopolitismen og modstanden mod menneskerettighederne hånd $i$ hånd (Krarup, 2000). Det er modstanden mod grænseløsheden. Former af disse kritikker reproduceres i antikosmopolitismens idéhistorie, men hver kritik af kosmopolitismen er selvsagt ikke reducerbar hertil. Ét forhold er dog permanent: grænsen overfor overskridelsen. Kosmopolitismen insisterer på grænsens overskridelse; dens kritikere insisterer på grænsens beståen eller nødvendighed.

Verena A. Conley (2002) har skabt et herligt begreb for verden som by: 'kaosmopolis', hvor enhver form kun er midlertidig, alt er flydende og kunne 
være anderledes, alt vil blive anderledes. Det er en verden af konstante genforhandlinger, af stadige genopfindelser af selvet og af evigt fluktuerende orienteringspunkter. Det antyder også ét af kosmopolitismens problemer: dets behov for overskud - både mentalt og økonomisk. Verden som by er uoverskuelig, rodet og krævende, og ikke alle vil føle sig hjemme eller tryg. Den engelske, konservative politiske tænker, Roger Scruton, sagde om kosmopolitten, at vedkommende "ofte ses som en form for parasit, der udnytter andres hverdagsliv til at skabe forskellige lokale smagsvarianter, som han kan svælge i" (citeret fra Waldron, 2000: 227). Man kan ikke bare summarisk afvise den kritik af kosmopolitismen, der betegner den som elitær og parasitær. Kosmopolitismen kræver mere end andre ismer. Oscar Wilde skrev engang, at et socialistisk demokrati var umuligt, fordi der ikke var aftener nok til alle de møder, der skulle til for at få det til at fungere. Man kan måske sige om kosmopolitismen, at der (endnu) kun er få, der har de ressourcer - den rejseaktivitet, økonomiske sikkerhed, uddannelse etc. - der skal til for at leve verdensåbent. Så når Richard Rorty i sin kritik af amerikanske venstreintellektuelle, Achieving Our Country, skriver, at "Denne nye kulturelle kosmopolitisme er forbeholdt de rigeste 25\% af amerikanerne" (1998: 85), så bliver vi nødt til at tage det alvorligt.

En opdateret udgave af den kritik ser en global politisk og økonomisk elite, der svigter det lokale og begrænsede, det kendte og kedelige til fordel for det globale og spændende, det økonomisk og personligt profitable liv i den globale overhalingsbane. Det er en velkendt og udbredt bekymring for demokratiets, den nationale kulturs og velfærdens fremtid i en globaliseret tidsalder, der ikke kun er forbeholdt regressive nationalister og velfærdschauvinistiske socialdemokrater (samt liberalister og konservative). Det er en gængs bekymring for en stadig større kløft mellem elite og befolkning, der opstår, fordi eliten har fået mulighed for at globalisere sig (se f.eks. Etzioni-Halevy, 1999; Crouch, 2000). Denne bekymring kan trække på en række klassiske, negative forestillinger om kosmopolitten. I det følgende vil jeg argumentere for, at dette ikke er et dækkende billede af den nye kosmopolitismes selvforståelse og erklærede projekt(er).

\section{Rodfastet kosmopolitisme}

Kosmopolitismens negative side er en mistænksomhedens filosofi, og med den følger altid faren for en følelse af moralsk overlegenhed, som kosmopolitismen ikke kan sige sig fri for til tider at tendere: "Den moralske kosmopolit 
... er ikke en, der føler sig hjemme alle steder, men en der overalt føler sig overlegen" (McConnell, 1996: 82). Det nye ved vor tids kosmopolitisme er erkendelsen af dens egne fordomme. Hvor den tidligere oplysningskosmopolitisme måske til tider med rette kunne beskyldes for enøjethed og selvforherligelse, så forsøger den nye kosmopolitisme at tage den mellemliggende periodes imperialisme og nationalisme alvorligt både som trussel, udfordring og besindelse.

Som David Hollinger gør opmærksom på, så er den nye kosmopolitisme hverken universalistisk eller pluralistisk (2001; se også Fine, 2003 samt bidragene i Cheah \& Robbins, 1998). Den nye kosmopolitisme kan tværtimod siges at lægge sig mellem universalismen og pluralismen. Han skriver: "For kosmopolitter er menneskehedens mangfoldighed et faktum; for universalister er den et problem. Kosmopolitter deler universalismens mistro overfor aflukkede rum, men forstår deres nødvendighed som kontingente og midlertidigt afgrænsede domæner, hvor mennesker kan have intime og varige forhold, og hvor de kan skabe mangfoldighed" (2001: 239). Et andet problem ved universalismen er dens politiske anvendelighed som dxkke for f.eks. imperialistiske projekter af kristen, liberal og marxistisk variant (Mehta, 2000: 622). Proklameret universalisme dækker ofte over partikulære politiske projekter, hvor ens nation, race, klasse, religion eller politik gøres til det universelt og selvfølgeligt sande.

Den nye kosmopolitisme vokser dog ud af den universalistiske indsigt, at nationale eller partikularistiske solidariteter truer større fællesskaber; at de umuliggør politik, der tager sit udgangspunkt i menneskeheden, eller i hvad Ulrich Beck kalder verdensrisikosamfundet (1996); samt at nationalismen ofte er endt i blodsudgydelser på 'fremmede' både indenfor staten og i konflikter mellem staterne. Men den nye kosmopolitisme afviser samtidig den 'klassiske kosmopolitisme' eller universalisme, der foreskriver én menneskehed som den eneste gyldige politiske og emotionelle enhed. Det anerkendes, at folk har behov for primære eller lokale identiteter, der er mindre end menneskeheden, men store nok til at handle politisk. Problemet med den nationalistiske pluralisme er dens kollektivisme; her er kosmopolitismen langt mere liberal og individualistisk, idet det enkelte menneske $\mathrm{i}$ både sin forskellighed som individ og sin ligeværdighed som menneske er den primære enhed i det politiske samfund.

Midt imellem disse to indsigter foreskriver den nye kosmopolitisme evnen til at manøvrere mellem en flerhed af identiteter, der er åbne og i stadig bevægelse, og som ikke kan reduceres til én fast identitet. Pluralister eller nationalister anerkender kun én identitet blandt en pluralitet af andre, også lukkede identiteter, og universalismen anerkender ingen enheder mindre end menne- 
skeheden. Den nye kosmopolitisme er derfor både kritisk overfor det, vi kan kalde det universalistiske venstre og det nationalistiske højre.

Et væsentligt element i den nye kosmopolitisme er bevægelsen fra kritik til løsning. Den nye kosmopolitisme er mere affirmativ end den klassiske; den er mere forpligtet på konkret forandring end på retoriske proklamationer af frihed, som den i vid udstrækning var begrænset til i sine første udgaver. Den søger nu at være konstruktiv og skabende i sin kritik.

\section{Kulturel kosmopolitisme: akademi, eksil og forbrug}

De kulturelle kosmopolitter kan deles op i tre grupper: de frivillige, de tvungne og de banale. De frivillige er oftest vestlige eller vestliggjorte intellektuelle, hvorimod de tvungne oftest er den tredje verdens vandrere. Det er akademiets overfor eksilets kosmopolitisme. Bauman (2004a) kalder de tvungne kosmopolitter for 'vagabonder', samtidig med at han reproducerer det gamle billede af kosmopolitten i sit billede af vagabondens modsætning $i$ 'turisten', der er den globalt rejsende - en skæbne han beskriver som både glædes- og oplevelsesløs i en verden af lufthavnsterminaler og hotelkæder. For at adskille den figur fra kosmopolitten vil jeg, med et udtryk fra Castells (1997: 67), kalde turisten for 'globapolit'- halvt menneske og halvt globale strømme; og Rüdiger Safranskis kritik af disse gør jeg til udgangspunkt for en bestemmelse af den kulturelle kosmopolit:

Hysteriet blandt mobilitetsatleter og global players må ikeke forveksles med verdensbefarenhed. En person, der passer sine verdensomspandende forretninger med skyklapper på eller rejser omkring som turist, er ikeke verdensbefaren. Hertil horer også en beredvillighed til at lade sig vikle ind $i$ det fremmede. Verdensbefaren er kun den, der er blevet forvandlet gennem rigdommen af verdenserfaring. (2004: 23)

I modsætning hertil er den kulturelle kosmopolit en, der frivilligt eller tvungent lader sig vikle ind i det fremmede. Den frivillige kosmopolit er oftest en, der fra et økonomisk og fysisk sikkert udgangspunkt - ofte den akademiske verden, men det kan også være fra en NGO eller international organisation - har et retfærdighedsbegreb, der ikke stopper ved landegrænsen. En af de fremmeste repræsentanter for denne position er Martha C. Nussbaum, der dels advokerer for en global forpligtelse på afhjælpning af nød og dels for en 
kosmopolitisk undervisningsplan i sit hjemland USA. I en appel til omlægning af det amerikanske undervisningssystem skriver hun (1996: 9):

Uddannelsesmassigt betyder det, at studerende $i$ US A f.eks. kan fortsatte med at se sig selv som delvist definerede af deres partikulare karligheder - til deres familier, deres religiose eller etniske fallesskaber og selv til deres land. Men de skal også og $i$ udpraget grad lare at anerkende menneskelighed, hvor end de finder den; de skal lare ikke at blive stodt bort af skikke, der er fremmede for dem; og de skal lare at forstå menneskeheden $i$ alle dens markelige former. De skal lare nok om det forskellige til at forstå de fallesmenneskelige mål, forbåbninger og vardier; og de skal lare nok om disse falles màl til at kunne se, hvor forskelligt de forsoges efterstrabt $i$ verdens mange kulturer og bistorier.

Den tvungne kosmopolit er immigranten, flygtningen, den eksilerede, der af bitter nødvendighed må lære at balancere mellem flere forskellige loyaliteter, tilknytninger og identiteter (Derrida, 1997; Nairn, 2003: 129). Den tvungne kosmopolit får endda i nogle diskurser næsten den samme rolle som proletariatet tidligere havde i marxistiske diskurser: nemlig som et forvarsel om eller en bærer af fremtiden (Hardt \& Negri, 2003). Deres hybriditet gør dem tilpasningsdygtige til en verden, der belønner flygtighed og omskiftelighed, mens national eller anden forankrethed straffes. Diaspora-samfundene - såvel som tredjeverdenslande, der som en del af deres 'nationale skæbne' ikke har oplevet nationalstatsdoktrinen om udelt suverænitet - er derfor modeller for fremtiden (Bauman, 2003: 166-7; Beck, 2004: 98).

Placeret imellem disse to grupper er ikke-vestlige, men vestligt bosiddende forfattere som f.eks. Edward Said, Salman Rushdie og V.S. Naipul (og herhjemme f.eks. Naser Khader), der til et vestligt publikum kritiserer ikke-vestlige befolkningsgruppers indsnævrethed til fordel for en bredere og blødere forståelse af identitet og loyalitet (Brennan, 1989; Cocks, 2000). Salman Rushdie er måske det bedste eksempel. Som Thomas Hylland Eriksen gør opmærksom på, så går Rushdie ind for den bastardiserede, kreoliserede og bevægelige verden, som han selv er en del af. Hans hovedmodstander er puritanernes krav om grænser og renhed (1999: 17). I en kommentar til terrorangrebene d. 11. september 2001 skriver Rushdie et stærkt forsvar for New York, der er en beskrivelse af verden som by befolket af glade bastarder: 
New York er den synlige verdens bankende hjerte, skrap i munden, fuld af liv, Walt Whitmans 'by af orgier, levemåder og nydelser', hans 'stolte og passionerede - fyrige, skore og ekstravagante by!' ... Sädanne folk [terroristerne, MT] er for bare at navne en kort liste imod ytringsfribed, flerpartisystem, almindelig og lige stemmeret, ansvarlig regeringskunst, joder, homoseksuelle, kvinders rettigheder, pluralisme, sekularisme, korte nederdele, dans, mand uden skacg, evolutionsteori, sex. ... Vi må blive enige om, bvad der er vigtigt: at kysse på offentlige steder, baconsandwicher, uenighed, den allernyeste mode, litteratur, generositet, vand, en mere ligelig fordeling af verdens ressourcer, biograffilm, musik, tankefribed, skonhed, karlighed. (2001)

Det er ikke uden betydning, at visse fundamentalistiske kristne grupper i USA jublede over angrebet på New York, som de kalder 'Jew York' i en klassisk antisemitisk metaforik over den fædrelandsløse, penge- og magtfikserede, udbyttende og depraverede, kosmopolitiske jøde. Fundamentalistiske muslimer og kristne står fælles i hadet til verden som by; den by, hvis arketypiske træk Rushdie meget præcist skildrer i citatet ovenfor.

Hylland Eriksen selv har i en interessant lille bog Kulturterrorismen med den sigende undertitel Et oppgjor med tanken om kulturell renhet begået et forsvar for urenheden; en "anarkistisk moralfilosofi for et flerkulturelt samfund", hvori han i bedste kosmopolitiske stil kritiserer, "hvordan kultur bliver gjort til en politisk ressurs", og hvori han "forsvarer individet mot fetisjeringen av 'kultur' som noe fast, permanent og autoritativt" (1999: hhv. 9, 23 \& 11). Kulturterrorisme er kosmopolittens begreb for det potentielt farlige i kulturaliseringen af vores tilværelse, hvad enten vi kulturaliserer os selv (i nationalismen) eller måske i god tro de andre (i multikulturalismen). Resultatet er, at identiteter låses fast i afgrænsede autarkiske enheder. Eriksens og kosmopolitismens mål er derimod at insistere på det midt-imellem, anomalierne, gråzonerne, det overskridende, det der aldrig vil kunne passe ind, det der stikker ud, det forstyrrende. Modstanderen er længslen efter renhed, entydighed, bestandighed, faste grænser etc.

Den tredje form for kulturel kosmopolitisme er den form, der hverken er villet eller tvunget, men levet. Det er en form, man kan kalde 'banal kosmopolitisme' eller 'banal globalisme', og den angår kulturernes og de kulturelle udtryksformers stadig større indlejring i transnationale fora (Held m.fl. 1999: kap. 7; Szerszynski \& Urry 2002; Held \& McGrew 2003: del 3). Ikke mindst gennem det globaliserede mediesystem vandrer symboler, ideer, udtryk etc. på tværs af grænser og blander sig med 'oprindelige' eller 'indfødte' kulturer. Den banale kosmopolitisme forbruges gennem mad, musik, mode, sportsbegivenheder, film etc. Men også gennem ideers, ideologiers og symbolers spredning. 
Frygten for dennne globalisering af kultur udtrykkes til tider i begreber som 'kulturens McDonaldisering' altså en global enhedskultur af ikke-mættende plastikkultur. Men det lader ikke til at være fremtiden. Det er snarere en globalisering af kulturerne; en 'forstyrrelse' af deres autonome reproduktionsproces, der åbner sig for hinanden uden at prisgive dem.

Kosmopolitismens forhåbning til denne 'banale kosmopolitisme' er, at den ved at opbløde kulturernes grænser, ved at eksponere verdens mangfoldighed, ved at tilbyde et utal af kulturelle og identitetsmæssige kombinationsmuligheder, vil fremelske en kosmopolitisk bevidsthed - ikke som erstatning for, men som et element i den lokale, etniske, religiøse, nationale etc. identitet.

\section{Kosmopolitisme som nationalt forraderi}

Hovedanklagerne mod den kulturelle kosmopolitisme er dens angivelige forræderi mod nationen samt dens alt for tynde sammenhængskraft. Selv Kant skrev om tyskerne: "de har ingen national stolthed og er alt for kosmopolitiske til at være stærkt forbundne med deres hjemland" (citeret fra Malcolmson, 1998: 238). Rousseau mente, at kosmopolitismen bare var en undskyldning for at kunne være ligeglad med sine landsmænd. I Genevé-udgaven af Samfundspagten skriver han desuden: "Det er ganske sikkert, at ordet menneskehed kun tilbyder mennesket en rent kollektiv idé, der ikke udgør nogen reel enhed blandt de individer, der udgør den" (1997: 155). Voltaire skrev i sin Filosofiske Ordbog om 'la Patrie', at "jo større fædrelandet er, desto mindre elsker vi det ... det er umuligt at stærkt elske en for stor familie, som vi dårligt nok kender”. Men i samme artikel skriver han som en forhåbning om det kosmopolitiske og som en erkendelse af dets grænse, at "Det er i menneskets natur, at ønske storhed for sit fædreland og dårligdomme for dets naboer. Verdensborgeren ville være manden, der aldrig ville ønske, at hans land var større eller mindre, rigere eller fattigere end nabolandet" (1972: hhv. 327 \& 329).

Den kommunitaristiske kritik af kosmopolitismen anfægter værdien og holdbarheden af den politiske enhed. Den fremhæver nationen, sproget, traditionen og historien som nødvendige elementer i funderingen af demokratiet, velfærden og identiteten; den kritiserer kosmopolitismen for at overdrive globaliseringens problematisering af det nationale skæbnefællesskab, og kosmopolitterne for at nedgøre det nationale og lokale til fordel for den tomme hyldest til det globale (se f.eks. Cohen 1996; Appiah 1998; se også Krarups kommentarer i dette nummer af Slagmark). Forholdet mellem kosmopolitisme, nationalisme og patriotisme er en af de væsentligste debatter i den nye 
kosmopolitisme. Den nye kosmopolitisme fremhæver evnen til at begå sig $\mathrm{i}$ flere og skiftende sammenhænge - også nationale - som det afgørende. David Held beskriver kulturel kosmopolitisme som "evnen til at mediere mellem nationale traditioner, skæbnefællesskaber og alternative livsstile" (2002: 37-8); og "Kosmopolitisme handler om at afdække det kulturelle, retslige og etiske grundlag for den politiske orden i en verden, hvor politiske fællesskaber og stater stadig har betydning, men ikke udelukkende og alene" (2003: 167-8). Stater og nationer eksisterer stadig og vil forblive væsentlige spillere både som politiske og kulturelle enheder; men de er ikke alene, og de kan ikke længere være lukkede, men må blive det, som Ulrich Beck kalder 'kosmopolitiske stater' (2002a, 2002b: kap. 4), der åbner sig for verden.

Den nye kosmopolitisme præsenterer sig som 'rodfæstet', 'indlejret', 'patriotisk', 'indfødt', 'situeret' etc. for at markere dens afstand til dele af sin egen fortid, til ideologierne om én verden og til den neoliberalistiske globaliseringsteori, der ser verden som et stort udifferentieret og statsløst marked. Kosmopolitismen er dog trods sin nye 'rodfæstelse' uvægerligt bundet til en mistro overfor det nationale og det statslige. Konfronteret med beskyldningen om at være national forræder vælger Günther Grass den rodløse kosmopolitisme frem for en aggressiv nationalisme (1990). Heri ligger kernen i kosmopolitismen: tvunget (af sine modstandere) til at vælge, så vil kosmopolitten altid vælge det universelle frem for det partikulære.

\section{Politisk kosmopolitisme; global demokratisering}

Politisk kosmopolitisme er en af vor tids mest innovative og ambitiøse forsøg på at begribe og reformere det globale system (Hutchings 1999). Det er hastigt ved at blive et samlebegreb for dels en filosofisk universalisering af retfærdighedsbegrebet; dels en teoretisk afklaring af forholdet mellem nationalisme, patriotisme og kosmopolitisme; og endelig dels en række meget konkrete politiske reformforslag. Denne genopdagelse af det kosmopolitiske er ikke mindst sket $i$ en kritisk genlæsning af Kants lille skrift Til den evige fred. Kant er blevet en afgørende referenceramme, da hans fredsskrift balancerer mellem kosmopolitisme og suverænitet, internationalisme og patriotisme på en måde, der åbner for en aktualisering i det, Habermas kalder 'den postnationale konstellation'.

Nogle af dens vigtigste repræsentanter er Richard Falk, Mary Kaldor, Daniele Archibugi, Thomas Pogge, Andrew Linklater, George Monbiot og ikke mindst David Held, der er ophavsmand til begrebet og programmet 'det kos- 
mopolitiske demokrati'. Man kan også sige, at både Habermas (1997: 134-5, 2001: 107-10) og Giddens (2004: 297ff) tenderer et kosmopolitisk projekt, hvorimod John Rawls (2002) forbliver liberal internationalist.

Retningen er opstået ud af en frustration over det liberale internationale regimes mangler (McGrew, 2001; Held \& McGrew 2002); det har ganske vist opnået betydelige fremskridt i efterkrigstiden - ikke mindst FN, menneskerettighedsregimet og de mange internationale samarbejder - men det forbliver låst fast $\mathrm{i}$ den geopolitiske aftale efter anden verdenskrigs afslutning, $\mathrm{i}$ et statscentristisk udgangspunkt og i en snæver liberalistisk økonomiopfattelse, der samlet står i vejen for en inddæmning af markedskræfterne, for en demokratisering af globale processer og for en humanisering af verdens forhold. Den kosmopolitiske strategi er at radikalisere visse elementer i det liberale internationale regime - ikke mindst styrkelsen af individet i forhold til staten. Ole Wæver udtrykker det ganske præcist, når han skriver, at "... realiseringen af en kosmopolitisk orden kræver en relativisering af staternes suverænitet og i praksis også, at man med direkte reference til menneskerettigheder handler på tværs af de regler, staterne har formuleret sig imellem i den givne folkeret" (2003: 67). Den politiske kosmopolitisme er derfor en udfordring af nationalstaten, af den Bodinske doktrin om suverænitet og af alle de begreber og praksisser, der er en del af det 'nationalstatsligt moderne'. Her finder vi derfor også den videnskabelige kosmopolitisme, der hævder, at de partikulære kategorier er overskredne. En af de væsentlige repræsentanter for denne kategori er Ulrich Beck, der med sit begreb om zombie-kategorier og sit udkast til et kosmopolitisk forskningsprogram (1998) har forsøgt at give stemme til en videnskabeligt funderet kritik af partikularismen som ganske enkelt ikke dækkende eller mulig i den globale eller anden modernitet.

Den politiske kosmopolitisme opstår ud af en analyse af globaliseringen, der fremhæver samfundenes stadig større forbundethed samt problemernes globalitet. Politiske kosmopolitter er kritiske overfor både den neoliberalistiske markedsglobalisering og den fundamentalistiske eller nationalistiske modrevolte. De ønsker en politisk globalisering, der ansvarliggør de processer, der angår hele verdens befolkning. Globaliseringen har placeret alle aktører og processer 'indenfor'; forestillingen om dem derude, som vi kan ignorere, bliver stadig mindre dækkende for virkeligheden og stadig mindre passende for praksissen. Det betyder også, at vores forpligtelser bliver globale, og at hvert enkelt menneske først og fremmest skal anerkendes som ligeværdigt menneske og ikke udelukkende som medborger eller ikke-borger. Spørgsmål om verdensborgerskab, delt statsborgerskab, plurale loyaliteter etc. trænger sig på (Heater, 1999: kap. 4; Hutchings \& Dannreuther, 1999), når det bliver stadig sværere at skelne mellem inde/ude, udenrigspolitik/indenrigspolitik, 
borger/fremmed, ven/fjende etc. Kosmopolitismen generelt og den politiske kosmopolitisme specielt siger ikke, at disse begreber fuldstændig mister værdi, men at de i stadig højere grad bliver uklare, omskiftelige, ustabile og genstand for stadige forhandlinger. Der er ikke længere (hvilket der aldrig var, men det så bare sådan ud) nogle entydige og selvfølgelige politiske kategorier, der kan distinktiere mellem borgere og ikke-borgere, mellem dem, vi har ansvar for og dem, vi kan være ligeglade med. Det stiller vores politiske institutioner, praksisser og fantasi overfor en stor opgave, som den politiske kosmopolitisme mener at have fundet en måde at begynde på at løse.

\section{En (god men) umulig drom}

Den mest gængse kritik af den politiske kosmopolitisme - fra kritikken af Kants projekt for evig fred og til i dag - er dens urealiserbarhed og naivitet; demokratiet når sin grænse ved landegrænsen; ethvert forsøg på at udstrække det videre fører ingen vegne. Et yndet argument er, at politisk kosmopolitisme vil indebære en verdensstat, der vil blive lige så hvis ikke mere tyrannisk end nationalstaterne. Det er dog mestendels et ikke-argument, da kosmopolitterne (igen fra Kant og frem) har været yderst opmærksomme på dette. Politisk kosmopolitisme handler netop om at demokratisere de skjulte og udemokratiske globale beslutningsprocesser, der allerede finder sted; ikke at opfinde nye ukontrollerede magter. Der er derfor ingen planer om en centralisering af magt på verdensplan. Selv ideen om f.eks. et verdensparlament skal bare ses som den logiske følge af magtens globalisering, hvorfor magtdelingen også bør følge efter.

Der er både en kommunitaristisk og realistisk variant af den kritik, der siger, at demokratiet og $i$ videre forstand programmer for lighed og retfærdighed ikke kan realiseres ud over nationalstatens grænser. Den kommunitaristiske er allerede omtalt, men en afart skal dog kort nævnes; nemlig den der eksplicit afviser, at vi har forpligtelser udenfor nationens grænser. En vulgær udgave af denne holdning finder vi f.eks. hos den tidligere spindoktor for kirkeminister Tove Fergo, Henrik Gade Jensen, der skriver: "Global ansvarlighed er en syg ide udtænkt i hovederne på mennesker, der opfatter jordkloden som et dukkehus, hvor der leges med indholdet” (1999). Den holdning er måske det bedste argument for kosmopolitismen.

Den realistiske kritik problematiserer både muligheden og nytten af en transnational demokratisering (Bull 1977: 84-8, 302-5; McGrew 1998; Dahl 1999; Held \& Hirst 2002). Det internationale er anarkisk; staterne forlader sig 
i sidste ende kun på sig selv og deres egen styrke; de interstatslige relationer er styret af snævre statsinteresser; og det internationale samfund er i bedste fald en tynd og skrøbelig konstruktion, men oftest bare en legitimering af stærke magters egeninteresse. Konflikt og magtanvendelse forbliver det internationales kendetegn. Realisterne er også ofte skeptiske overfor globaliseringstesen og ikke mindst overfor påstanden om nationalstatens snarlige endeligt (som de dog ikke hører fra de nye kosmopolitter, men snarere fra markedsliberalisterne).

Der findes også en radikal kritik, der beskylder kosmopolitismen for - bevidst eller ubevidst - at tjene de stærke geopolitiske og økonomiske kræfters sag. Denne kritik anklager også kosmopolitismen for at være endnu en udgave af eurocentrisme eller endda imperialisme (Hawthorn 2000; Chandler 2000; Brennan 2001; Gowan 2001). I et citat fra en marxistisk filosofisk ordbog forklares en ældre marxistisk kritik af kosmopolitismen, der beskylder den for forræderi mod først og fremmest klassen og ikke som det oftest ses udelukkende mod nationen:

Kosmopolitisme: det ideologiske udtryk for det opadstrabende bourgeoisis klasseinteresse. ... Det imperialistiske bourgeoisis nutidige kosmopolitisme er reaktionar og tjener som undskyldning for det nationale forrederi samt som begrundelse for og retfardiggorelse af monopolkapitalismens forening. Kosmopolitismen er skyggesiden af den borgerlige nationalisme og chawinisme. Den er det reaktionare modstykke til den socialistiske internationalisme. (Philosophisches Wörterbuch 1971: 667)

Den nye radikale kritik ser den kosmopolitiske kritik af national suverænitet som dække for installeringen af et globalt frihandels- og interventionsregime styret af kapitalistiske og vestlige interesser. Kosmopolitismen svækker nationalstaterne, samtidig med at den legitimerer for såkaldte 'humanitære interventioner' imod besværlige regimer, der ikke vil underlægge sig det neoliberalistiske frihandelsregime. Påberåbninger af det kosmopolitiske eller verdenssamfundet tjener de stærkeste magters interesser, da de er de eneste, der effektivt kan handle på vegne af 'verdenssamfundet'; kosmopolitisme bliver derfor legitimeringsgrundlaget for en 'liberal imperialisme' (Zolo, 1997, 2002). Selvopfattelsen hos den politiske kosmopolitisme er dog snarere den, at de forbinder sig med det fremvoksende globale civilsamfunds forhåbninger om en mere retfærdig fordeling af klodens prioriteter, ressourcer og muligheder. Deres kritik af den eksisterende globale orden er mindst lige så stærk som den, der kommer fra den radikale kritik. 


\section{Den kosmopolitiske tanke}

Teoretisering om livet på en kugleoverflade har måske engang varet en luksus, som man bedst kunne hengive sig til fjernt fra verdens vrimmel $i$ det trygge og provinsielle Königsberg. Men som klodens indbyggere nu gennem daglig erfaring er ved at lare på den bårde måde, og som politikerne i sidste ende også må se i gjnene, stär dette sporgsmål nu overst på den menneskelige overlevelses dagsorden. (Bauman, 2004b:28)

Ikke mindst siden Benedict Anderson (2001) har vi vidst, at det nationale samfund er forestillet. Det globale samfund er ingen undtagelse. Der er intet 'naturligt' eller 'selvfølgeligt' ved det. Det skal konstrueres som alle andre fællesskaber. Man kan sige, at den kulturelle kosmopolitisme forsøger at skabe den relationelle infrastruktur og den politiske kosmopolitisme den institutionelle infrastruktur, der skal gøre det muligt at træde ind i kosmopolitismens tidsalder.

Bauman peger på et væsentligt problem $\mathrm{i}$ den henseende: "Det 'internationale samfund' har ingen realitet andet end de militære operationer, der foretages i dens navn" (2001: 15). Han forudser, at det sandsynligvis er ud af de krige ført af (vestlige) koalitioner af villige, at det internationale samfund (hvis overhovedet) vil blive en realitet. Kosmopolitterne deler den frygt, da det internationale samfund i givet fald vil blive en forstørret udgave af vesten og dens interesser og dermed en forvrængning af det kosmopolitiske til et nyt forsvar for vestlig imperialisme og hegemoni.

Men kosmopolitterne har samtidig en bredere forståelse af det internationale samfunds realitet. De ser det som beskrevet ovenfor overalt. Så de siger, som Kant sagde om oplysningen, at vi ikke lever i en kosmopolitisk tidsalder men $\mathrm{i}$ en kosmopolitiseringens tidsalder. Og de siger videre, som Kant sagde: "Vi ser dog tydelige tegn på, at det i det mindste bliver muligt, at man frit kan arbejde sig hen imod dette, og at hindringerne for den almene oplysning eller for udgangen af den selvforskyldte umyndighed efterhånden bliver mindre" (1996: 78). Som Kant så registrerer de 'tegn' på frigørelsen fra det partikulære misregimente som f.eks. udviklingen af menneskeretsregimet, den nye internationale straffedomstol, væksten $i$ interkulturelle møder, samhandel og samliv, EU, FN's konferenceaktivitet, røret i det globale civilsamfund fra neden, 
der organiserer og mobiliserer transnationalt etc. Det ser de som tegn på, at aflukkede enheder ikke vil kunne opretholde sig selv i fremtiden; at åbenhed er den eneste overlevelses-, sikkerheds- og velfærdsstrategi.

Man kan også lidt bredere kalde det for 'den kosmopolitiske tanke', der er et såvel deskriptivt som normativt udsagn om den rette anskuelsesmåde. Det partikulære - inde/ude, ven/fjende, os/dem, lokalt/nationalt/globalt - sammenfiltres eller overskrides, hvilket på ingen måde er problemfrit. Men det tilbyder dog en mulighed til dem, der måtte ønske det, eller som vil kæmpe for det. Thomas Hylland Eriksen får det sidste ord (1999: 59): "Verden består ikke af afgrænsede kulturer. Den består af over fem milliarder mennesker som i varierende grad er præget af forskellige kulturelle former og traditioner, der både overlapper og udviser stor individuel variation. Renhed og entydige grænser er fantasifostre skabt af ofre for streng pottetræning. Verden er uren og består af et mylder af gråzoner."

\section{Litteraturliste}

Litteraturlisten er tænkt som en hjælp til den videre læsning og er derfor opdelt efter artiklens afsnit. Man vil her kunne finde den refererede litteratur og andre artikler/bøger, der angår emnet.

\section{Indledning}

Castells, Manuel (1997). The Information Age, vol. 2: The Power of Identity, Oxford: Blackwell. Calhoun, Craig (2002). "The Class Consciousness of Frequent Travelers: Toward a Critique of Actually Existing Cosmopolitanism”, South Atlantic Quarterly, vol. 101, nr. 4, s. 869-895. Lasch, Christopher (1995). Eliternes opror og forraderiet mod demokratiet, Kbh: Hovedland.

\section{Den nye kosmopolitisme}

Beck, Ulrich (1996). "World Risk Society as Cosmopolitan Society?", Theory, Culture \& Society, vol. 13, nr. 4, s. 1-32.

Burke, Edmund (1987). Tanker om den franske revolution, Ribe: Tidehverv.

Buruma, Ian \& Avishai Margalit (2004). Occidentalism. The West in the Eyes of Its Enemies, New York: Penguin.

Cheah, Pheng \& Bruce Robbins (1998). Cosmopolitics - thinking and feeling beyond the nation, Minneapolis: Minneapolis University Press.

Cohen, Mitchell (1992). "Rooted Cosmopolitanism”, Dissent, fall, s. 478-83.

Conley, Verena Andermatt (2002). "Chaosmopolis", Theory, Culture \& Society, vol. 19, nr. 1-2, s. 127-138.

Etzioni-Halevy, Eva (1999). "Elites, Inequality and the Quality of Democracy in Ultramodern Society", International Review of Sociology, vol. 9, nr. 2, s. 239-250.

Crouch, Colin (2000). Coping with Post-democracy, London: Fabian Society. 
Fine, Robert (2003). “Taking the 'Ism' out of Cosmopolitanism”, European Journal of Social Theory, vol. 6, nr. 4, s. 451-470.

Heater, Derek (1996). World Citizenship and Government - Cosmopolitan Ideas in the History of Western Thought, London: Macmillan.

Hobbes, Thomas (1985). Leviathan, London: Penguin.

Hollinger, David A. (2001). "Not Universalists, Not Pluralists: The New Cosmopolitans Find Their Own Way", Constellations, vol. 8, nr. 2, s. 236-248.

Kleingeld, Pauline (1999). "Six varities of cosmopolitanism in late eighteent-century Germany", Journal of the History of Ideas, vol. 60, nr. 3, s. 505-524.

Kleingeld, Pauline (2003). "Kant's Cosmopolitan Patriotism", Kant-Studien, vol. 94, s. 299316.

Kleingeld, Pauline \& Eric Brown (2002). "Cosmopolitanism", Stanford Encyclopedia of Philosophy, http://plato.stanford.edu.entries.cosmopolitanism.

Krarup, Søren (2000). Dansen om menneskerettighederne, København: Gyldendal.

Lettevall, Rebecka (2001). En europeisk kosmopolit. En idébistorisk studie av Immanuel Kants Om den evigea freden och dess verkningshistoria, Stockholm: Brutus Östlings Bokförlag.

Maistre, Joseph de (1974). Considerations on France, Montreal \& London: McGill-Queen's University Press.

McConnell, Michael W. (1996). "Don't neglect the little platoons" i Joshua Cohen (red.), For Love of Country. Debating the Limits of Patriotism, Boston: Beacon Press.

Mehta, Pratap Bhanu (2000). "Cosmopolitanism and the circle of reason", Political Theory, vol. 28 , nr. 5 , s. 619-639.

Nichols, Mary P. (1986). "Kant's teaching of Historical Progress \& Its Cosmopolitan Goal”, Polity, vol. 19, s. 194-212.

O’Brien, Karen (1997). Narratives of Enlightenment. Cosmopolitan history from Voltaire to Gibbon, Cambridge: Cambridge University Press.

Rorty, Richard (1998). Achieving Our Country. Leftist thought in twentieth-century America, Cambridge, Mass.: Harvard University Press.

Schlereth, Thomas (1997). The Cosmopolitan Ideal in Enlightenment Thought, Notre Dame: University of Notre Dame Press.

Taguieff, Pierre-André (1997). "The Traditionalist Paradigm - Horror of Modernity and Antiliberalism" i Luc Ferry \& Alain Renaut (red.), Why we are not Nietzscheans, Chicago \& London: University of Chicago Press.

Waldron, Jeremy (2000). "What is Cosmopolitan?", Journal of Political Philosophy, vol. 8, nr. 2, s.227-243.

\section{Kulturel kosmopolitisme}

Appiah, Kwame A. (1998). "Cosmopolitan Patriots" i Pheng Cheah \& Bruce Robbins (1998). Cosmopolitics - thinking and feeling beyond the nation, Minneapolis: Minneapolis University Press.

Bauman, Zygmunt (2003). Flydende kecrlighed, Kbh: Hans Reitzel.

Bauman, Zygmunt (2004a). "Om glokalisering: Eller globalisering for nogle, lokalisering for andre" i Mikkel Thorup (red.), At tanke globalt, Kbh: Hans Reitzel.

Beck, Ulrich (2002a). "The Terrorist Threat. World Risk Society Revisited", Theory, Culture \& Society, vol. 19, nr. 4, s. 39-55.

Beck, Ulrich (2002b). Ordenes tavshed. Om terror og krig, Kbh: Hans Reitzel.

Beck, Ulrich (2004). "Det kosmopolitiske perspektiv: en sociologi for det andet moderne" 
i Mikkel Thorup (red.), At tanke globalt, Kbh: Hans Reitzel .

Beitz, Charles (1983). "Cosmopolitan Ideals and National Sentiment", Journal of Philosophy, vol. 80 , nr. 1, s. 591-600.

Brennan, Tim (1989). "Cosmopolitanism and Celebrities", Race \& Class, vol. 31, nr. 1, s. 1-19.

Canovan, Margaret (2001). "Sleeping dogs, prowling cats and soaring doves: three paradoxes in the political theory of nationhood", Political Studies, vol. 49, s. 203-215.

Cocks, Joan (2000). "A New Cosmopolitanism? V.S. Naipaul and Edward Said", Constellations, vol. 7, nr. 1, s. 46-63.

Cohen, Joshua, red. (1996). For Love of Country. Debating the Limits of Patriotism, Boston: Beacon Press.

Colás, Alejandro (1994). "Putting Cosmopolitanism into Practice: the Case of Socialist Internationalism”, Millennium, vol. 23, nr. 3, s. 515-534.

Derrida, Jacques (1997). On Cosmopolitanism and Forgiveness, London \& New York: Routledge.

Eriksen, Thomas Hylland (1999). Kulturterrorismen. Et oppgjor med tanken om kulturell renhet, Oslo: Spartakus.

Erskine, Toni (2002). "Citizen of nowhere or the point where circles intersect? Impartialist and embedded cosmopolitanisms", Review of International Studies, vol. 28, s. 457-478.

Grass, Günther (1990). "Short Speech by a Rootless Cosmopolitan”, Dissent, fall, s. 458460 .

Hardt, Michael og Toni Negri (2003). Imperiet, København: Informations Forlag.

Harris, Lee (2003). "The Cosmopolitan Illusion", Policy Review, april/maj, s. 45-59.

Held, David (2002). "Law of States, Law of Peoples: Three Models of Sovereignty", Legal Theory, vol. 8, nr.1, s. 1-44.

Held, David (2003). "From Executive to Cosmopolitan Multilateralism" i D. Held \& M. Koenig-Archibugi (red.), Taming Globalization. Frontiers of Governance, London: Polity.

Held, David m.fl. (1999). Global Transformations, Cambridge: Polity.

Held, David \& Anthony McGrew, red. (2003). The Global Transformations Reader, Cambridge: Polity.

Knippenberg, Joseph (1989). "Moving beyond fear: Rousseau and Kant on Cosmopolitan Education", Journal of Politics, vol. 51, nr. 4, s. 809-827.

Kymlicka, Will (1999). "Citizenship in an era of globalization: commentary on Held" i Ian Shapiro \& Casiano Hacker-Cordón (red.), Democracy's Edges, Cambridge: Cambridge University Press.

Lu, Catherine (2000). "The One and Many Faces of Cosmopolitanism”, Journal of Political Philosophy, vol. 8, nr. 2, s. 244-267.

Malcomson, Scott L. (1998). "TheVarities of Cosmopolitan Experience” i Pheng Cheah \& Bruce Robbins (red.), Cosmopolitics. Thinking and Feeling beyond the Nation, Minneapolis: University of Minnesota Press.

McCarthy, Thomas (1999). "On reconciling cosmopolitan unity and national diversity", Public Culture, vol. 11, nr. 1, s. 175-208.

Nairn, Tom (2003). “A Myriad Byzantiums”, New Left Review, nr. 23, s. 115-133.

Nava, Mica (2002). "Cosmopolitan Modernity. Everyday Imaginaries and the Register of Difference", Theory, Culture \& Society, vol. 19, nr. 1-2, s. 81-99.

Nussbaum, Martha C. (1996). "Patriotism and Cosmopolitanism" i Joshua Cohen (red.), For Love of Country. Debating the Limits of Patriotism, Boston: Beacon Press. 
Nussbaum, Martha C. (2000). "Duties of Justice, Duties of Material Aid: Cicero's Problematic Legacy", Journal of Political Philosophy, vol. 8, nr. 2, s. 176-206.

Nussbaum, Martha C. (2004). "Kant og stoisk kosmopolitisme”, Slagmark, nr. 41.

Parekh, Bhikhu (2003). "Cosmopolitanism and global citizenship", Review of International Studies, vol. 29, s. 3-17.

Rousseau, Jean-Jacques (1997). "Of the Social Contract/Genevé-manuskriptet”, i Rousseau, The Social Contract and other later political writings, red. af Victor Gourevitch, Cambridge: Cambridge University Press.

Rushdie, Salman (2001). "Fighting the forces of invisibility", Washington Post, 2. oktober.

Safranski, Rüdiger (2004). Hvor meget globalisering tåler mennesket?, Kbh: Akademisk Forlag.

Søelund, Lise (2002). Kulturens vilkår i en globaliseringstid, Kbh: Akademisk Forlag.

Szerszynski, Bronislaw \& John Urry (2002). "Cultures of Cosmopolitanism", Sociological Review, November, s. 461-481.

Toynbee, Polly (2001). "Who's Afraid of Global Culture?" i Will Hutton \& Anthony Giddens (red.), On the Edge: Living with global capitalism, London: Vintage.

Turner, Bryan S. (2002). "Cosmopolitan Virtue, Globalization and Patriotism", Theory, Culture \& Society, vol. 19, nr. 1-2, s. 45-63.

Venn, Couze (2002). "Altered States. Post-Enlightenment Cosmopolitanism and Transmodern Socialities”, Theory, Culture \& Society, vol. 19, nr. 1-2, s. 65-80.

Voltaire, Francois M.A. de (1972). Philosophical Dictionary, London: Penguin.

Urry, John (2000). "The Global Media and Cosmopolitanism”, www.comp.lancs.as.uk/ sociology/papers/Urry-Global-Media.pdf.

\section{Politisk kosmopolitisme}

Archibugi, Daniele (1993). "The Reform of the UN and Cosmopolitan Democracy: A Critical Review", Journal of Peace Research, vol. 30, nr. 3, s. 301-315.

Archibugi, Daniele (1995). "Immanuel Kant, Cosmopolitan Law and Peace", European Journal of International Relations, vol. 1, nr. 4, s. 429-456.

Archibugi, Daniele (1998). "Principles of Cosmopolitan Democracy" i D. Archibugi, D. Held \& m. Köhler (red.), Re-imagining Political Community, Cambridge: Polity Press.

Archibugi, Daniele (2000). "Cosmopolitical democracy", New Left Review, nr. 4, s. 137150.

Archibugi, Daniele (2002). "Demos and Cosmopolis", New Left Review, nr. 13, s. 24-38.

Archibugi, Daniele (2003). "A Critical Analysis of the Self-determination of Peoples: A Cosmopolitan Perspective", Constellations, vol. 10, nr. 4, s. 488-505.

Beck, Ulrich (1998). "The Cosmopolitan Manifesto", New Statesman, 20. marts.

Beitz, Charles (1999). "Social and cosmopolitan liberalism", International Affairs, vol. 75, nr. 3, s. 515-529.

Bohman, James (1999). "Citizenship and norms of publicity. Wide public reason in cosmopolitan societies”, Political Theory, vol. 27, nr. 2, s. 176-202.

Bohman, James (2001). "Cosmopolitan republicanism: citizenship, freedom and global political authority", Monist, vol. 84, nr. 1.

Bohman, James \& Matthias Lutz-Bachmann, red. (1997). Perpetual Peace - Essays on Kant's Cosmopolitan Ideal, Cambridge: MIT Press.

Brennan, Tim (2001). "Cosmopolitanism and Internationalism”, New Left Review, nr. 7, s. 75-84.

Brown, Chris (2002). 'The construction of a 'realistic utopia': John Rawls and international 
political theory", Review of Political Studies, vol. 28, s. 5-21.

Bull, Hedley (1977). The Anarchical Society. A Study of Order in World Politics, London: Macmillan.

Chandler, David (2000). "International Justice”, New Left Review, nr. 6, s. 55-66.

Chandler, David (2003). "New Rights for Old? Cosmopolitan Citizenship and the Critique of State Sovereignty", Political Studies, vol. 51, s. 332-349.

Dahl, Robert (1999). "Can international organizations be democratic?” i Ian Shapiro \& Casiano Hacker-Cordón (red.), Democracy's Edges, Cambridge: Cambridge University Press Falk, Richard (1995). "Liberalism at the global level: the last of the independent commissions?”, Millennium, vol. 24, nr. 3, s. 563-576.

Falk, Richard (1999). "The Pursuit of International Justice: Present Dilemmas and An Imagined Future", Journal of International Affairs, vol. 52, nr. 2, s. 409-441.

Falk, Richard \& Andrew Strauss (2001). "Toward Global Parliament”, Foreign Affairs, vol. 80 , nr. 1, s. 212-220.

Franceschet, Antonio (2000). "Popular Sovereignty or Cosmopolitan Democracy? Liberalism, Kant and International Reform", European Journal of International Relations, vol. 6, nr. 2, s. 277-302.

Giddens, Anthony (2004). "At tage globaliseringen alvorligt" i Mikkel Thorup (red.), At tanke globalt, Kbh: Hans Reitzel.

Gowan, Peter (2001). "Neoliberal Cosmopolitanism", New Left Review, nr. 11, s. 79-93.

Görg, Christoph \& Joachim Hirsch (1998). "Is International democracy possible?", Review of International Political Economy, vol. 5, nr. 4 s. 585-615.

Guneriussen, Willy (2004). "Globalisering: Trenger vi nye begrep om samfunn, fellesskap og demokrati?”, Distinktion, nr. 8, s. 93-112..

Habermas, Jürgen (1997). "Kant's Idea of Perpetual Peace, with the Benefit of Two Hundred Years' Hindsight" i J. Bohman \& M.Lutz-Bachmann (red.), Perpetual Peace, Cambridge: MIT Press.

Habermas, Jürgen (2001). The Postnational Constellation, Cambridge: Polity Press.

Harvey, David (2000). "Cosmopolitanism and the Banality of Geographic Evils", Public Culture, vol. 12, nr. 2, s. 529-564.

Hawthorn, Geoffrey (2000). "Running the World through Windows", New Left Review, nr. 5, s. $101-110$.

Heater, Derek (1999). What is Citizenship?, Cambridge: Polity.

Held, David (1995). Democracy and the Global Order, Cambridge: Polity.

Held, David (2004). The Global Covenant, Cambridge: Polity.

Held, David \& Anthony McGrew (2002). Globalization/Anti-Globalization, Cambridge: Polity.

Held, David \& Paul Hirst (2002). "Globalisation after 11 september - the argument of our time. OpenDemocracy dialogues between David Held and Paul Hirst", www.opendemocracy.net.

Hutchings, Kimberly (1999). International Political Theory, London: Sage.

Hutchings, Kimberly \& Roland Dannreuther, red. (1999). Cosmopolitan Democracy, London: Macmillan.

Højholt, Jeppe (2002). "Globalisering og demokrati - det kosmopolitiske perspektiv", Grus, vol. 23, nr. 67, s. 87-102.

Jensen, Henrik Gade (1999). "Global ansvarlighed er en syg ide", Politiken, 11. september. Jones, Deiniol (2003). "The origins of the global city: ethics and morality in contemporary 
cosmopolitanism", British Journal of Politics and International Relations, vol. 5, nr. 1, s. 50-73. Kaldor, Mary (1999). New and Old Wars - organized violence in a global era, Stanford: Stanford University Press.

Kaldor, Mary (2000). "Europe at the Millennium”, Politics, vol. 20, nr. 2, s. 55-62.

Kaldor, Mary (2003a). "American power: from 'compellance' to cosmopolitanism?", International Affairs, vol. 79, nr. 1, s. 1-22.

Kaldor, Mary (2003b). "Global Terrorism” i Anthony Giddens (red.), The Progressive Manifesto, Cambridge: Polity.

Kaldor, Mary (2004). "Nationalism and Globalisation", Nations and Nationalism, vol 10, nr. 1-2, s. 161-177.

Kant, Immanuel (1995). Til den evige fred, Kbh: Gyldendal.

Kuper, Andrew (2000). "Rawlsian Global Justice", Political Theory, vol. 28, nr. 5, s. 640674.

Laffey, Mark (2001). "Tall tales of the state and its trials: the world according to liberal cosmopolitanism", Politologiske Studier, nr. 2, s. 74-81.

Linklater, Andrew (1999). The Transformation of Political Community, Cambridge: Polity.

McGrew, Anthony (1998). "Realism vs. cosmopolitanism. A debate between Barry Buzan and David Held", Review of International Studies, vol. 24, s. 387-398.

McGrew, Anthony (2000). "Democracy beyond borders?” i Held \& Mcgrew (red.), The Global Transformations Reader, Cambridge: Polity.

McGrew, Anthony (2001). "Demokratisering af det globale samfund: teorier og muligheder", Grus, nr. 64, s. 59-78.

Monbiot, George (2003). The Age of Consent - a manifesto for a new world order, London: Flamingo.

Muhtu, Sankar (2000). "Justice and Foreigners: Kant's Cosmopolitan Right", Constellations, vol. 7 , nr. 1, s. 23-45.

Pagden, Anthony (2000). "Stoicism, Cosmopolitanism, and the Legacy of European Imperialism", Constellations, vol. 7, nr. 1, s. 3-22.

Philosophisches Wörterbuch (1971), red. af Georg Klaus \& Manfred Buhr, Leipzig: VEB Bibliographisches Institut.

Pogge, Thomas (1992). "Cosmopolitanism and Sovereignty", Ethics, oktober, s. 48-75.

Pogge, Thomas (1994). "An Egalitarian Law of Peoples", Philosopby and Public affairs, vol. 23, nr. 3, s. 195-224.

Politologiske Studier (2001). "Temanummer om kosmopolitisme".

Rawls, John (2002). The Law of Peoples, Cambridge, Mass.: Harvard University Press.

Scheuerman, William (2002). "Cosmopolitan Democracy and the Rule of Law", Ratio Juris, vol. 15 , nr. 4 , s. $439-57$.

Søndergaard, Jens Teilberg (2003a). Ret, demokrati og globalisering. Om kosmopolitanisme og empirisme, Kbh: Jurist- og Økonomforbundets Forlag.

Søndergaard, Jens Teilberg (2003b). "Fra Den evige fred til Empire - et essay om ret, fred og frihed i lyset af globaliseringen”, Distinktion, nr. 6, s. 99-110.

Tully, James (2002). "The Kantian Ideal of Europe: Critical and Cosmopolitan Perspectives" i Anthony Pagden (red.), The Idea of Europe, Cambridge: Cambridge University Press.

Williams, Howard (2003). Kant's Critique of Hobbes. Sovereignty and Cosmopolitanism. Woodiwiss, Anthony (2002). "Human Rights and the Challenge of Cosmopolitanism", Theory, Culture \& Society, vol. 19, nr. 1-2, s.139-155.

Wæver, Ole (2003). "Europafilosofi”, Kritik, nr. 166, s. 65-69. 
Zolo, Danilo (1997). Cosmopolis: Prospects for World Government, Cambridge: Polity. Zolo, Danilo (1999). "A Cosmopolitan Philosophy of International Law? A Realist Perspective", Ratio Juris, vol. 12, nr. 4, s. 429-44.

Zolo, Danilo (2000). "The lords of peace. From the holy alliance to the new international criminal tribunals" i Barry Holden (red.), Global Democracy. Key debates, London: Routledge Zolo, Danilo (2002). Invoking Humanity: War, Law and Global Order, London \& New York: Continuum.

\section{Den kosmopolitiske tanke}

Anderson, Benedict (2001). Forestillede fallesskaber - refleksioner over nationalismens oprindelse og udbredelse, Frederiksberg: Roskilde Universitetsforlag.

Bauman, Zygmunt (2001). "Wars of the Globalization Era", European Journal of Social Theory, vol. 4, nr. 1, s. 11-28.

Bauman, Zygmunt (2004b). Det belejrede samfund, Kbh: Hans Reitzel.

Kant, Immanuel (1996). "Besvarelse af spørgsmålet: Hvad er oplysning?" i Morten Haugaard Jeppesen (red.), Immanuel Kant: Oplysning, historie, fremskridt, Århus: Slagmarks Skyttegravsserie. 